Thorax 1987;42:827-828

\title{
Effect of ethanol on transfer factor: the importance of posture
}

\author{
D J LYONS, H MOSZORO, T J PETERS, J S MILLEDGE \\ From the Divisions of Anaesthesia and Clinical Cell Biology, Medical Research Council, Clinical Research \\ Centre, Harrow, Middlesex
}

Pulmonary diffusing capacity for carbon monoxide (transfer factor, TLCO) is known to be low in alcoholics, ${ }^{1}$ and ethanol may cause a reduction in TLCO in normal subjects. ${ }^{2}$ The mechanism of this reduction is unclear, but there are two possible explanations. Firstly, a redistribution of blood may occur between the central and peripheral vasculature, causing a fall in pulmonary capillary blood volume (Vc). Secondly, there may be a change in the function of the alveolar capillary membrane (DM). Distinction between these two possibilities is important as it has been claimed on the basis of the alcohol induced reduction in TLCo that ethanol is directly toxic to the pulmonary alveolar capillary membrane. $^{2}$ To elucidate the mechanism of the fall in TLCO after ethanol we measured TLCO, Vc, and DM in normal subjects in both the erect and supine positions, before and 90 minutes after taking ethanol.

\section{Methods}

We studied 12 normal men aged 21-53 (mean 31) years; three were ex-smokers and nine had never smoked. All were in good health. They fasted from midnight on the day before the study. All experiments started at $1 \mathrm{pm}$. The subject lay flat on an examination couch or sat upright on a chair for 10 minutes before the measurements were carried out. TLCO was measured in duplicate by the single breath method described by Ogilvie et al. ${ }^{3}$ All measurements were made at total lung capacity (TLC). The order in which measurements were made (that is, whether the subjects were sitting or supine) was assigned randomly. The subjects then drank $1.5 \mathrm{ml}$ of gin ( $45 \%$ ethanol) per $\mathrm{kg}$ body weight diluted with an equal volume of fruit juice. The measurements were repeated after 90 minutes and blood was drawn for determination of serum ethanol and haemoglobin concentrations.

Initially we studied TLCo alone in five subjects to see if we could repeat the previously observed fall after ethanol. Data from these subjects (not shown separately) convinced us that there was a fall. In the subsequent seven subjects we measured DM and Vc in addition to TLCO. Subjects in whom DM and $\mathrm{VC}$ were measured did not differ in any way from the group as a whole. DM and VC were measured in the sitting and supine positions by the technique of Roughton and Forster. ${ }^{4}$ In this method TLCO is measured in duplicate with trace concentrations of carbon monoxide in air and in $80 \%$ oxygen.

Address for reprint requests: Dr D J Lyons, Clincial Research Centre, Harrow, Middlesex HA1 3UJ.

Accepted 19 January 1987

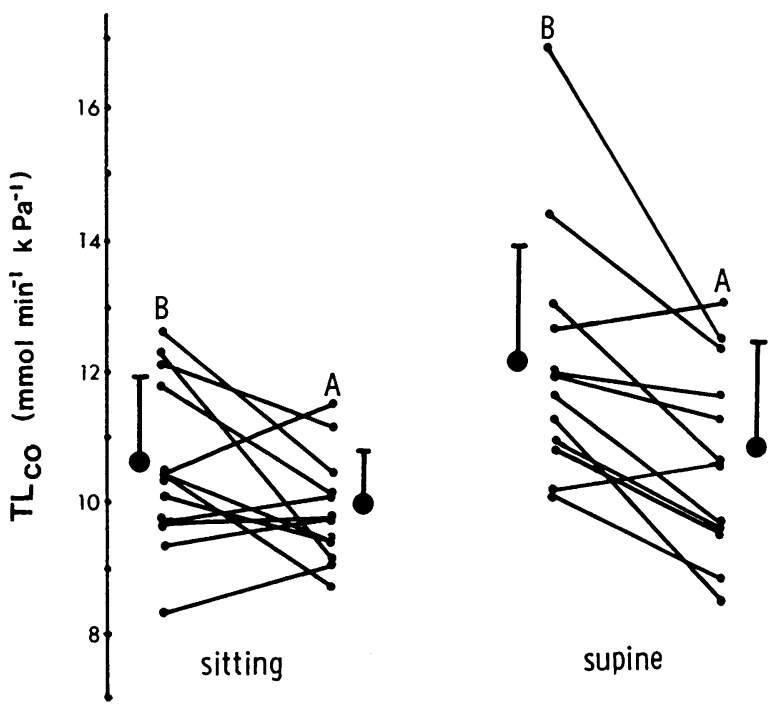

Fig 1 Transfer factor TLCo measurements before (B) and after (A) ethanol in 12 normal subjects determined in sitting and supine positions. Large symbols indicate group means and standard deviations. Statistical analysis by Student's paired t test gave values of $p>0.05$ in the sitting position and $p<0.02$ in the supine position.

\section{Results}

In preliminary experiments the variability of the tests was assessed. TLCo was measured in four subjects on at least eight occasions each, and the coefficient of variation was less than $7 \%$. VC and DM were measured in one subject on 12 occasions with coefficients of variation of $11 \%$ and $21 \%$ respectively. TLCo was within the predicted normal range for all subjects, and values of DM and Vc were similar to those previously reported. ${ }^{5}$ Effective alveolar volume was larger in the sitting position (mean (SD) 6.1 (1.4) l) than the supine $(5.9(1.0) 1)$, but it did not vary with inhaled oxygen concentration and did not change after ethanol. All subjects absorbed sufficient ethanol to give detectable concentrations; at 90 minutes the mean serum ethanol concentration was 54 (range $38-68$ ) $\mathrm{mg} / 100 \mathrm{ml}$. 


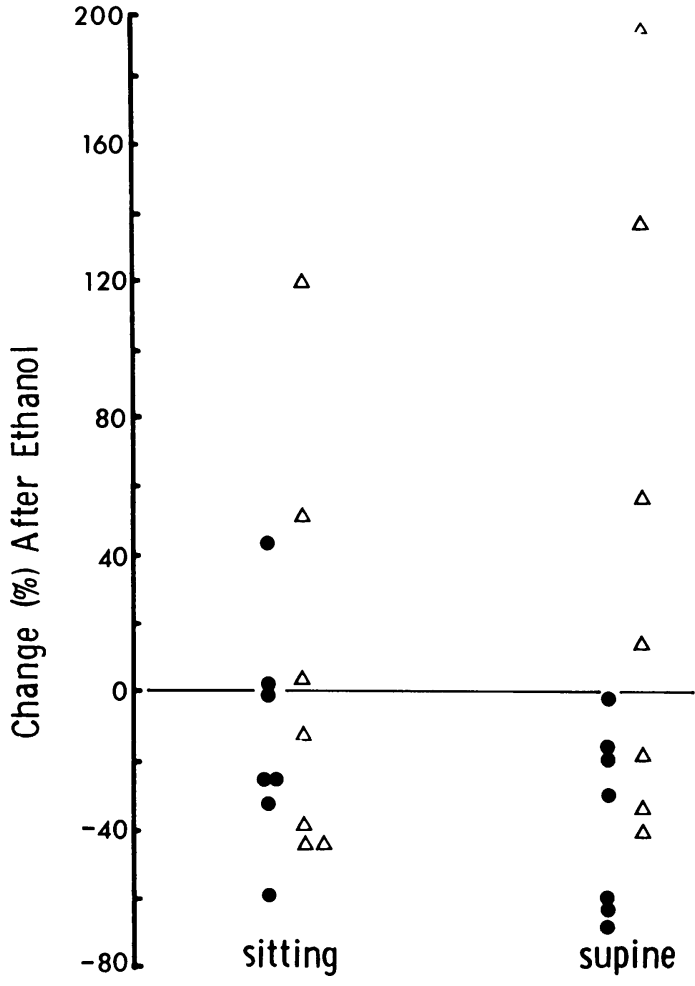

Fig 2 Percentage change in $D_{M}(\Delta)$ and $V_{C}(O)$ in individual subjects after ethanol in sitting and supine positions in seven normal subjects.

A significant drop in TLco from 11.9 (SD 1.9) to 10.6 (1.2) $\mathrm{mmol} \mathrm{min}-1 \mathrm{kPa}^{-1}$ was noted in the supine position 90 minutes after ethanol ( $\mathrm{p}<0.02$ by paired $t$ test) (fig 1 ). A much smaller drop from $10.5(1.2)$ to $9.8(0.8)$ mmol $\min ^{-1} \mathrm{kPa}^{-1}$ was found in the sitting position and this was not significant.

There was a significant fall in Vc from 144 (SD 84) to 75 $(15) \mathrm{ml}$ in the supine position $(\mathrm{p}<0.05)$. The fall in $\mathrm{V}_{\mathrm{c}}$ in the sitting position $(95(44)$ to $76(33) \mathrm{ml})$ was not significant. DM did not change significantly after ethanol in either the supine or sitting position (fig 2).

\section{Discussion}

Our results showing a mean reduction of $11 \%$ in TLCo when this was measured in the supine position 90 minutes after ethanol ingestion agree closely with those of Peavy et al, ${ }^{2}$ who found a mean fall of $14 \%$ one hour after ethanol. Theyes reported measurements made only in the supine position Our subjects were studied both sitting and supine and we् found a much smaller change in the sitting position. There is therefore an important positional effect on the reduction in TLCO induced by ethanol. Our results show a failure of the expected physiological increase in TLCo with the changeis from sitting to supine positions after ethanol.

The normal rise in TLCo on lying down is thought to be due to an increase in pulmonary capillary blood volume. ${ }^{5} \vec{\omega}$ Ethanol causes an increase in cardiac output at blood con- $\omega$ centrations similar to those found in this study, ${ }^{6}$ and it causes peripheral vasodilatation. Probably this results in $a^{x}$ shift of blood from the pulmonary to the peripheral circu-N lation. This may be more pronounced in the supine position $\vec{\circ}$ because of the greater resting vasomotor tone in the upright $t_{0}$ posture. ${ }^{7}$ This suggestion is supported by our measurements ${ }^{N}$ of DM and Vc. Although there was considerable variation ino DM between individuals, the results for any one individual were consistent and did not decrease after ethanol. In con- $\overrightarrow{-}$ trast, VC closely followed the change in TLCO, showing an significant fall in the supine position.

The fall in Vc, together with the important effect of pos-迎 ture on the changes in TLCo brought about by ethanol, lead us to conclude that the effect of ethanol on TLCO is mediated $\odot$ by a change in pulmonary capillary blood volume.

\section{References}

1 Banner AS. Pulmonary function in chronic alcoholism. Am Rev Respir Dis 1973;108:851-7.

2 Peavy HH, Summer WR, Gurtner G. The effects of acute ethanol ingestion on pulmonary diffusing capacity. Chest 1980;77:488-92.

3 Ogilvie C, Forster R, Blakemore W, Morton J. A standardised breath holding technique for the clinical measurement of the diffusing capacity of the lung for carbon monoxide. $J$ Clin Invest 1957;36:1-17.

4 Roughton FJ, Forster RE. Relative importance of diffusion and $\underset{\mathfrak{X}}{\times}$ chemical reaction rates in determining rate of exchange of gases in the human lung. With special reference to tissue diffusing capacity of pulmonary membrane and volume of $\Omega$ blood in the lung capillaries. $J$ Appl Physiol 1957;11:290-302.

5 Lewis B, Lin T, Noe F, Komisaruk R. The measurement of pulmonary capillary blood volume and pulmonary membrane $\mathrm{O}$ diffusing capacity in normal subjects; the effects of exercise and $I$ position. J Clin Invest 1958;37:1061-70.

6 Juchems R, Kolbe R. Hemodynamic effects of ethyl alcohol in man. Am Heart J 1969;78:133-5.

7 Brigden W, Howarth S, Sharpey-Schafer EP. Postural changes in the peripheral blood-flow of normal subjects with observation $\mathrm{N}$ on vasovagal fainting reactions as a result of tilting, the $N$ lordotic posture, pregnancy and spinal anaesthesia. Clin Sci 1950;9:79-90. 